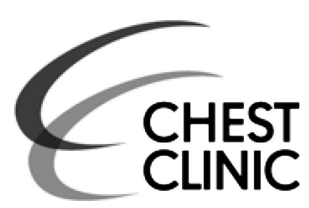

'Department of Thoracic Surgery, Iwate Prefectural Central Hospital, Morioka, Japan

${ }^{2}$ Department of Pathology, Iwate Prefectural, Central Hospital, Morioka, Japan ${ }^{3}$ Department of Thoracic Surgery, Miyagi Cancer Center, Natori, Japan

${ }^{4}$ Department of Thoracic Surgery, Institute of Development, Aging and Cancer, Tohoku University, Sendai, Japan

\section{Correspondence to} Dr Jiro Abe, Department of Thoracic Surgery, Miyagi Cancer Center, 47-1 Nodayama, Medishima-Shiote, Natori, Miyagi 981-1239, Japan;

jabe@kmph.mfnet.ne.jp

Received 19 November 2012 Revised 23 January 2013 Accepted 28 January 2013 Published Online First 15 February 2013

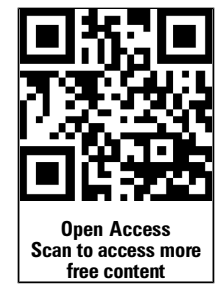

To cite: Abe J, Oura $\mathrm{H}$, Niikawa $\mathrm{H}$, et al. Thorax 2014;69:97-98.

\title{
Dendriform pulmonary ossification: unusual cause of spontaneous pneumothorax
}

\author{
Jiro Abe, ${ }^{1,3}$ Hiroyuki Oura, ${ }^{1}$ Hiromichi Niikawa, ${ }^{1,4}$ Hiroshi Yaegashi, ${ }^{2}$ Takashi Kondo ${ }^{4}$
}

A 53-year-old man was admitted to our hospital with a recurrence of spontaneous pneumothorax. He had no history of other diseases including chronic lung diseases. A month prior to this admission, he had a first pneumothorax and was treated with 4 days of intercostal drainage. CT scan showed no bulla, but revealed multiple small polygonal lesions consistent with fibrotic lesions mainly in the right lower lobe (figure 1). We performed right thoracotomy and found that air leakage arose from torn visceral pleura which had been pierced by a drumstick-shaped bony structure (figure 2A). Some other solid flat lesions were palpable in the lung. They were almost confluent, and had a dendriform appearance. We removed the bony tissue, and repaired the torn pleura. Pathological exam revealed that this was mature bone with normal marrow (figure 2B). The patient has been healthy without a further pneumothorax since the operation.

\section{LEARNING POINTS}

Spontaneous pneumothorax caused by pulmonary ossification is a rare event though pulmonary ossification is not so uncommon. A previous report described that pulmonary ossification had been observed in $0.4 \%$ of all autopsy cases. ${ }^{1}$

While many basic diseases such as congestive heart failure, pulmonary fibrosis, diabetes mellitus and other metabolic diseases can cause secondary pulmonary ossification, primary pulmonary ossification is of unknown aetiology and is called idiopathic pulmonary ossification. Pathologically, idiopathic pulmonary ossification is classified into two forms: dendritic (tree-like branched) pulmonary ossification (DPO) and nodular pulmonary ossification. ${ }^{1}$

CT scan images of dendritic pulmonary ossification show irregular nodules which are discrete or are joined to each other; they typically form a dendriform lesion. Calcified high density lesions are not always seen on radiological imaging even though mature bone tissue is demonstrated in such lesions under the microscope. ${ }^{2}$

\section{Competing interests None.}

Patient consent Obtained.

Ethics approval Research ethics committee of Central Hospital of Iwate Prefecture.

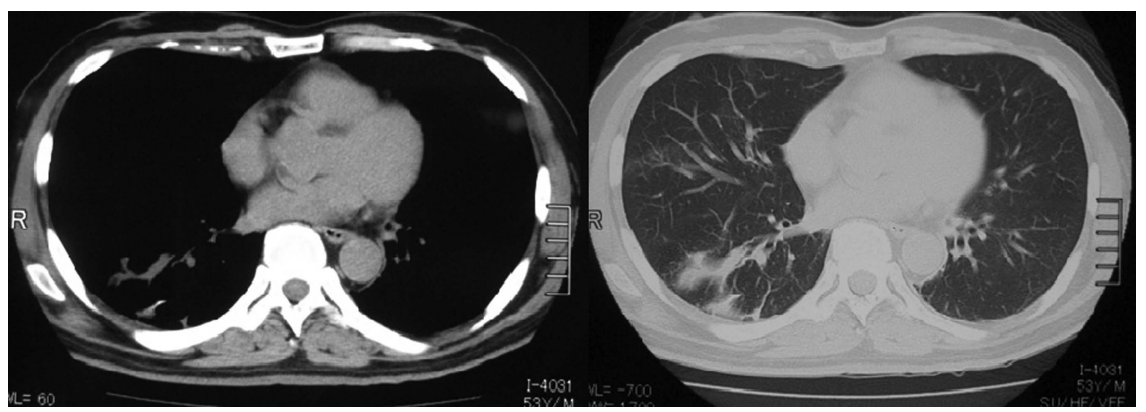

Figure 1 CT scan images of dendritic pulmonary ossification patient show dendriform irregular lesions in right lower lobe. A calcified deposit can be seen in one lesion, though calcification is not dominant.

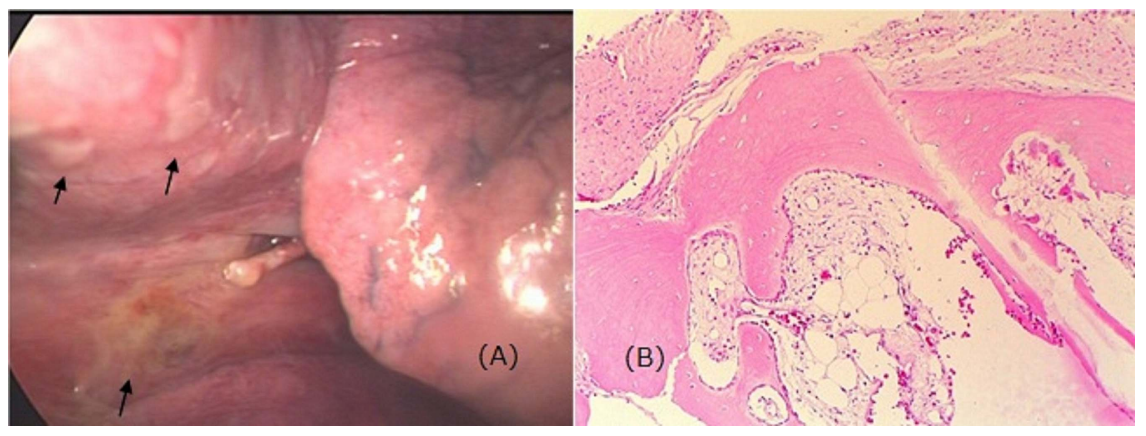

Figure 2 In the centre of the photo, a drumstick-shaped bony solid tissue arose from inside the lung, and pierced the visceral pleura. Air leakage from the tear could be found during the operation. Irregular yellowish lesions under the pleura were dominant in the lower lobe (black arrows). (B) Microscopic view of the drumstick. Trabeculated mature bone structure with normal marrow was observed. 
Provenance and peer review Not commissioned; internally peer reviewed.

Open Access This is an Open Access article distributed in accordance with the Creative Commons Attribution Non Commercial (CC BY-NC 3.0) license, which

\section{REFERENCES}

1 Lara JF, Catroppo JF, Kim DU, et al. Dendriform pulmonary ossification, a form of diffuse pulmonary ossification. Arch Pathol Lab Med 2005;129:348-53.

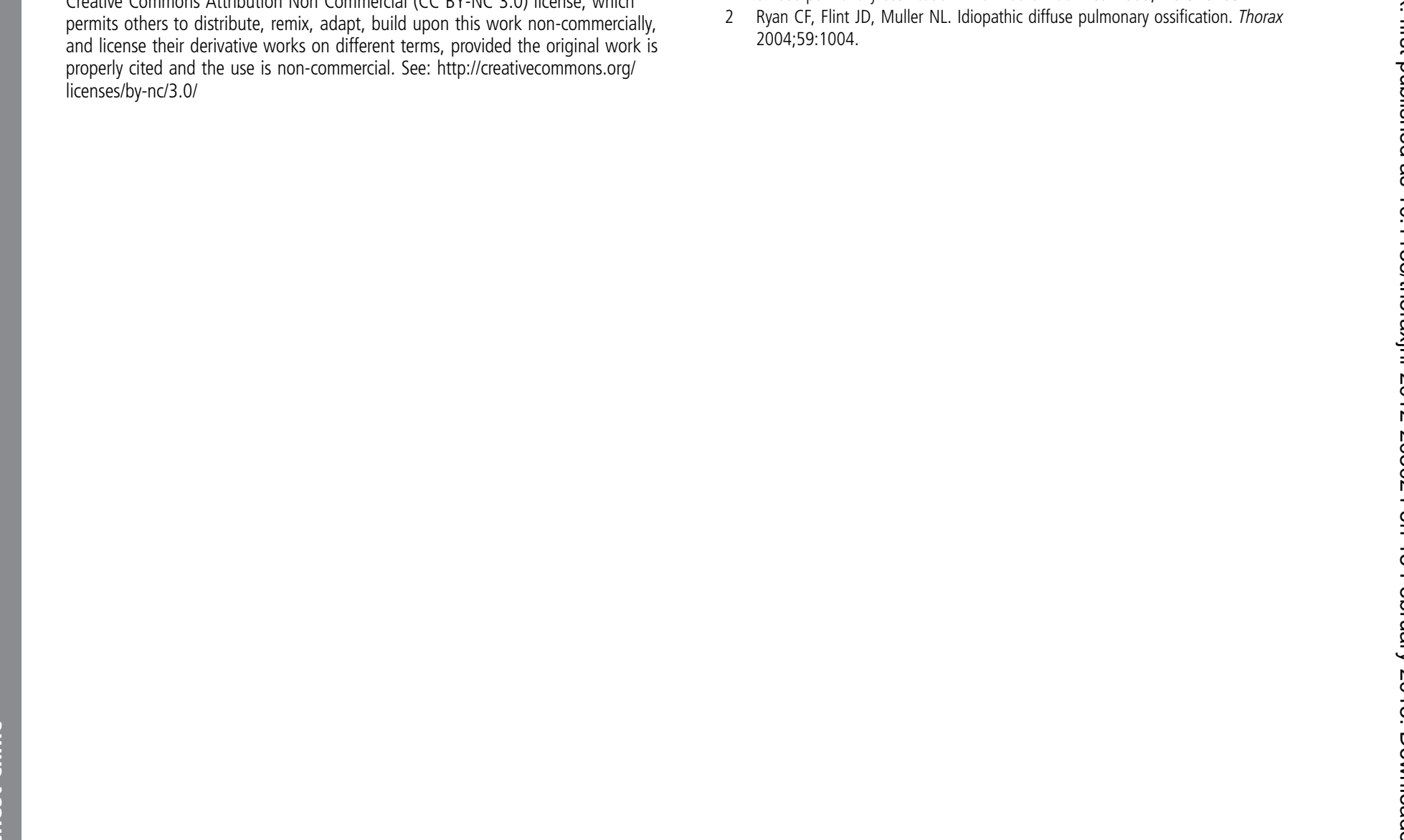

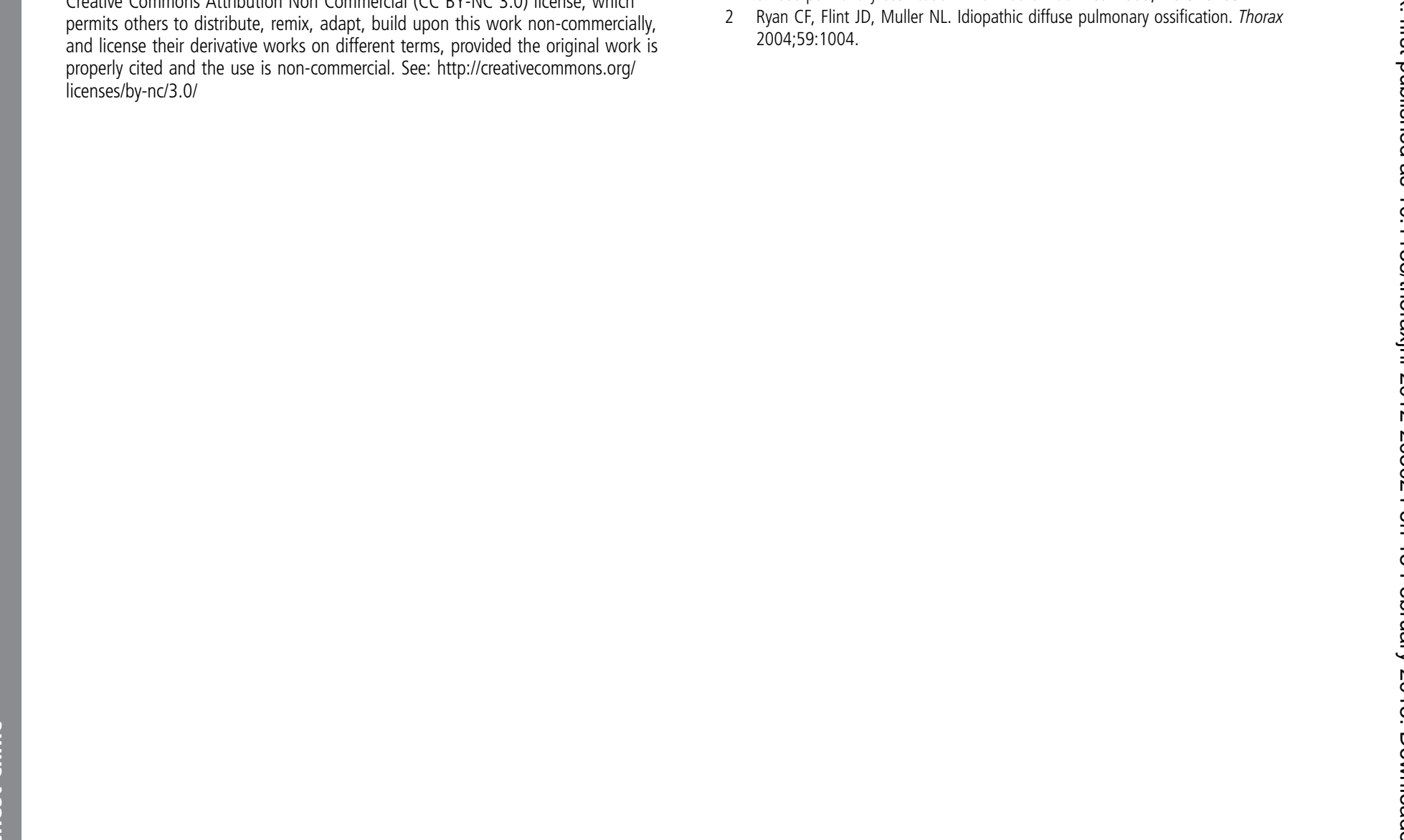

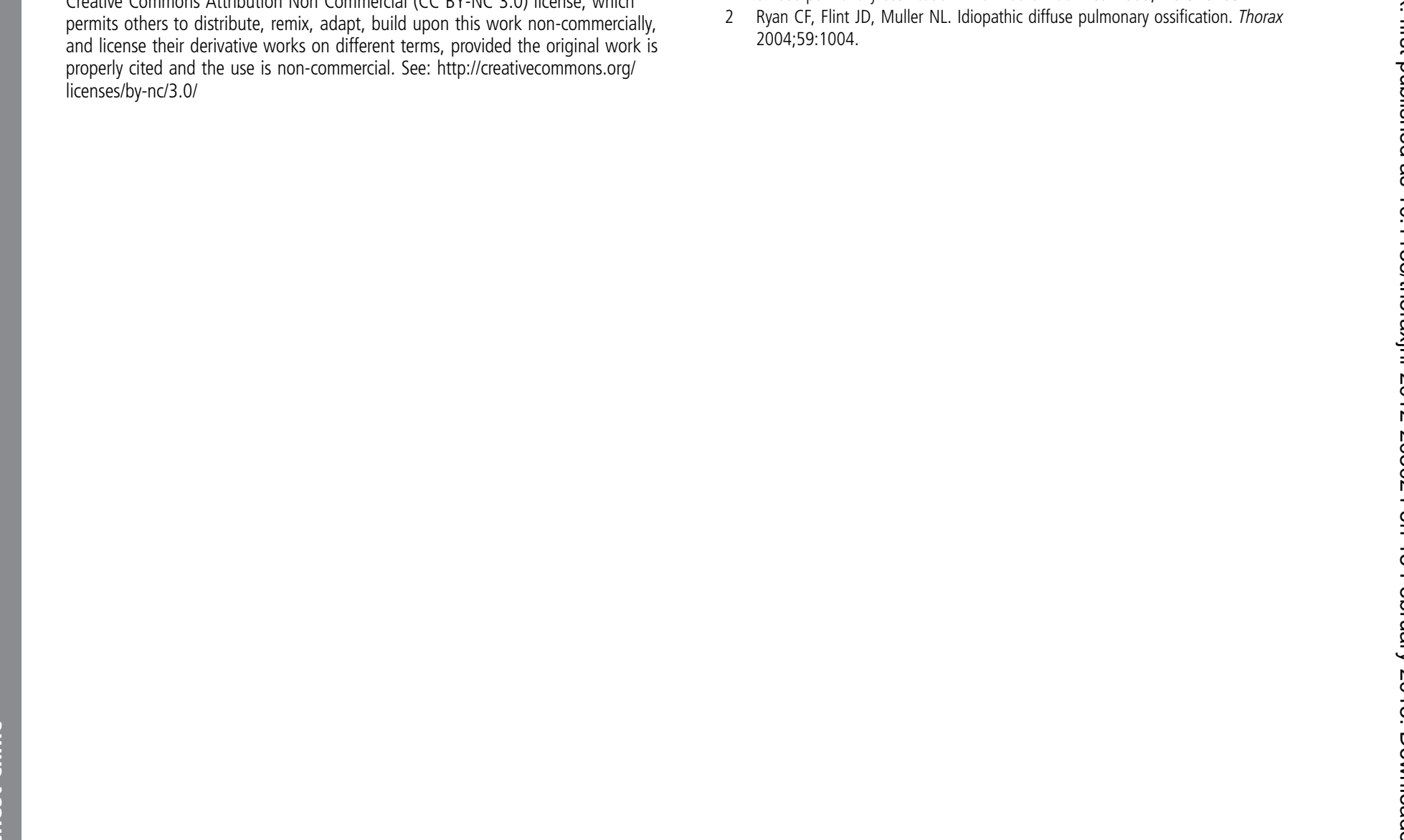

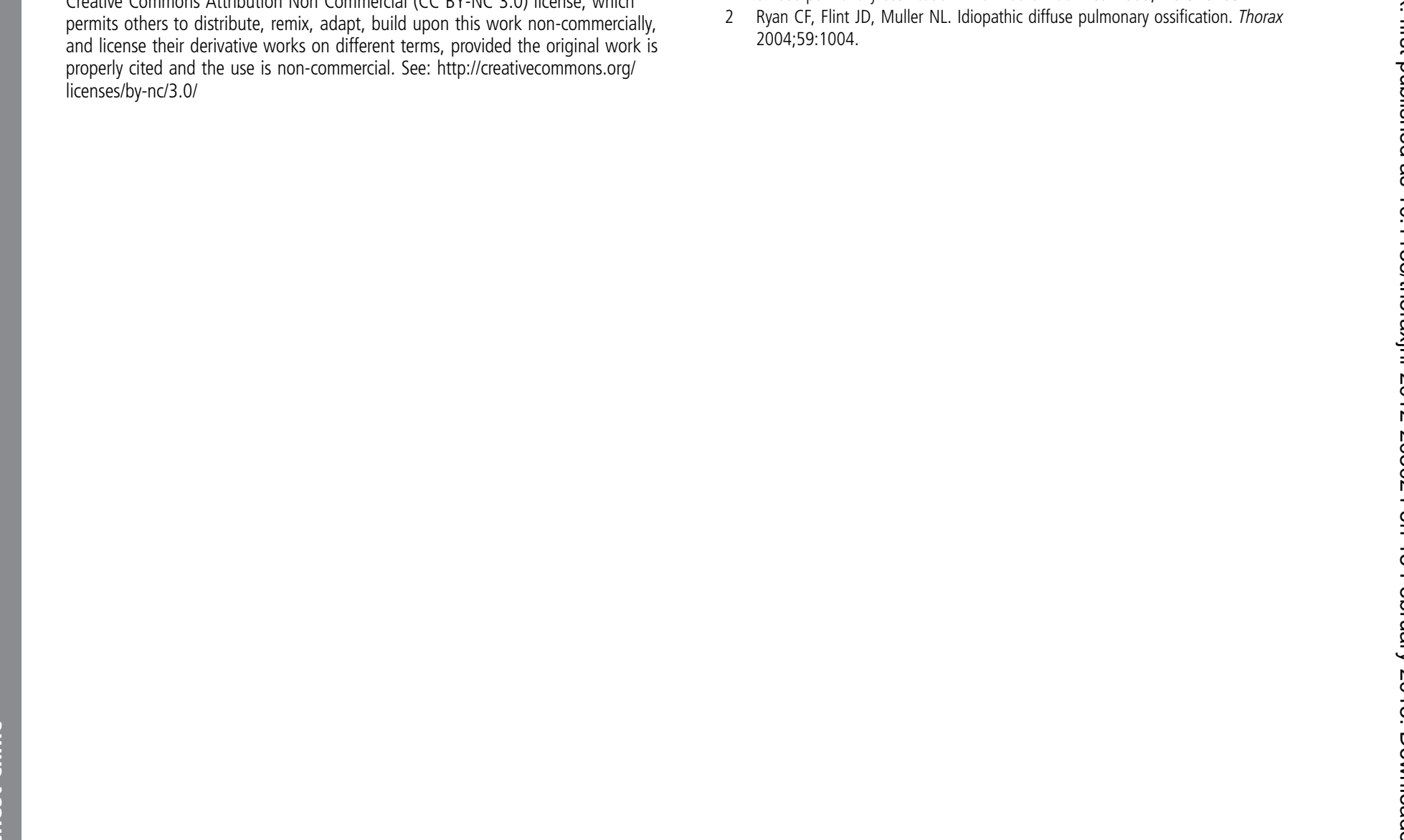

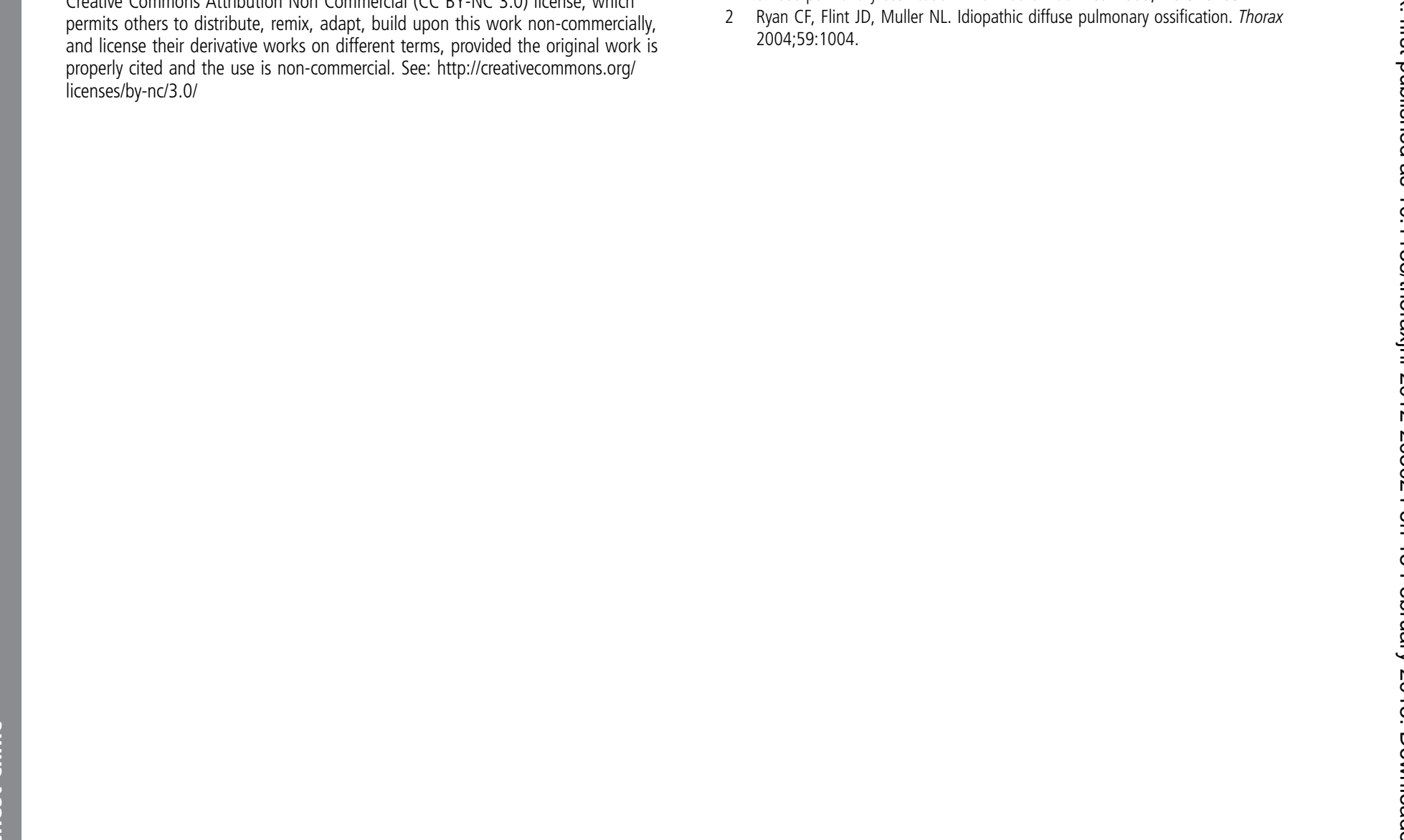

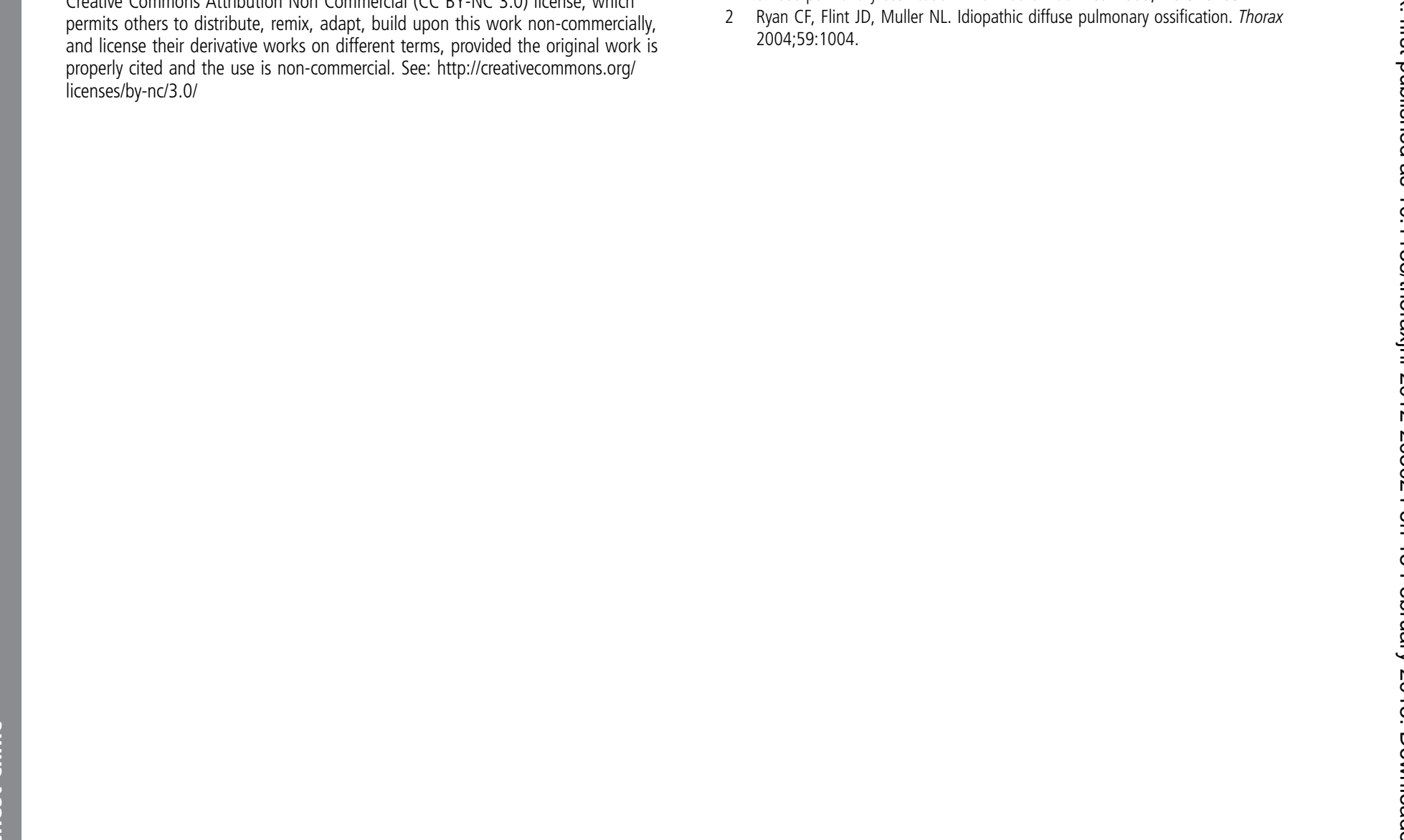

